\title{
René, Werther y La Nouvelle Hélö̈se en la Primera Novela de la Avellaneda
}

$\mathrm{H}$ ACE ya casi el siglo -en I 867 - Juan Valera afirmaba que Gertrudis Gómez de Avellaneda como "poetisa lírica no tiene ni tuvo nunca rival en España y seria menester, fuera de España, retroceder hasta la edad más gloriosa de Grecia, para hallarle rivales en Safo y en Corina, si no brillase en Italia, en la primera edad del siglo xvi, la bella y enamorada Victoria Colonna".' Sin embargo, en ese mismo ensayo Valera aseguraba que en cuanto a la obra novelesca de la Avellaneća no sólo tenía que cederle la palma a la francesa Jorge Sand sino también quedaba "muy por bajo, en fama y merecimiento". ${ }^{2}$ Conviene señalar que en esta ocasión Valera intentaba - a toda costa, al parecer- de poner sobre las nubes la obra lírica de la Avellaneda. Dejándose empujar por su prurito de encarecer y quizá con el propósito de hacer sus aseveraciones más aceptables, coloca las novelas de la cubana en lugar muy inferior. Desde luega estos juicios deben rechazarse porque ni la lírica merece la más alta esfera celestial ni la prosa una condenación a un dudoso limbo literario. Téngase en cuenta que el no estar a las alturas de Aurore Dupin no se debe considerar gran desprestigio. George Sanc' no se puede estimar prosista de poco mérito y según algunos la mujer que espantó a los burgueses de todo un continente constituye uno de los valores más notables de la novela

I Obias completas (Madrid, 1949), II, 376.

2 lbid. Valera no le concedía mucha importancia al género novelesco: "Las ideas que había expuesto ocasionalmente en algunos artículos sobre novelas y novelistas - es el más interesante quizá el titulado $D e$ la naturaleza y carácter de la novela, 1860-tampoco parecían indicar en el expositor ni gran comprensión ni gran entusiasmo por el género. Se hubiera dicho que Valera sentia, heredado también del siglo xviII, un cierto menosprecio por estas obras «de imaginación» o «de entretenimiento», crmo las llamó siempre..." José F. Montesinos, Valera o la ficción libre (Madrid, 1957), p. 20. 
francesa del siglo XIX. ${ }^{3}$ De cualquier modo, parece que el juicio negativo cie Valera ha prevalecido: la crítica apenas si se ha ocupado de las novelas de la Avellaneda. ${ }^{4}$ Actualmente si la obra de Gertrudis Gómez de Avellaneda goza de cierta gloria literaria esto se puede atribuir casi exclusivamente a su poesía y teatro; lo que se ha escrito sobre sus narraciones ha sicio en general bastante insignificante. Por eso merece interés especial el importante ensayo que la profesora Helena Percas Ponseti ha dedicado a la novelita $S a b .^{5}$ Sin querer aminorar de manera alguna la aportación de ese valioso estudio, quizá convenga proponer algunas precisiones sobre las fuentes literarias que pudieron influir en la composición de $S a b$. No es que creamos que la búsqueda de fuentes tenga valor intrínseco, pero sí abrigamos la esperanza de que, enfocando el asunto desde esta perspectiva, se nos revele algo de las intenciones de la joven Avellaneda.

En 1836,6 cuando apenas contaba 22 años, Gertrudis Gómez de Avellaneda - voraz lectora que siempre fue- ya se había nutricio de innumerables lecturas que le comenzaban a inspirar algunas composiciones en prosa y otras en verso. De Alfonse de Lamartine, la joven cubana escribía en una carta: "Lamartine, uno de los más grandes poetas de la moderna escuela y acaso el más dulce y fácil, tiene, sin embargo, algo de vago y metafísico en su poesía, y una manera de decir que es ciertamente intraducible". ${ }^{\text {? }}$ De modo que no se puede uno asombrat al descubrir que en el primer volumen de poesías de la Avellaneda se encontraban varias traducciones e imitaciones del autor de Les méditations poétiques. ${ }^{8}$

3 André Maurois nos dice que Marcel Proust leía con placer las novelas de George Sand [recuérdese que en $A$ la recbercbe du temps perdu (Paris, 1962), I, 39-42, Proust menciona esas lecturas] y que Alain hablaba de la autora de Indicana can mucho respeto ("Cette grande dame"). Flaubert la llamaba "ma chère maître". Véase Andrés Maurois, Lélia (Paris, 1952), p. 7.

"Una novela solamente se suele mencionar de vez en cuando: Guatimozín. Esto hay que lamentar porque Guatimozin, con todo su exotismo seductor, su cuidadosa documentación, $y$ sus ideas generosas y nobles, de ninguna manera representa el mejor esfuerzo novelesco de la Avellaneda.

5 "Sobre la Avellaneda y su novela Sab" Revista Iberoamericana, XXVIII (julio-diciembre 1962), pp. 347-357.

6 La Avellaneda afirmó haber comenzado a escribir $S a b$ en 1836. Véase $L a$ Ilustración (Madrid, 1850), p. 351. En 1844, sin embargo, escribió en una carta al señor A. Neira que habia empezado su novelita en Portugal el año 1838. Esta carta se publicó en el estudio de Emilio Cotarelo y Mori, "La Avellaneda y sus cbras", Boletín de la Redl Academia Española (1930), p. 186.

7. Autabiografía y sartas, $2^{7}$ ed. (Madrid, 1914), p. 116.

8 Habia también traducciones e imitaciones de otros poetas. Se ha estudiado este aspecto en nuestra tesis, "L'Inspiration étrangère chez Gertrudis Gómez de Avellaneda", 394 págs., tesis para el doctorat d'université, Universidad de París, 1961. 
También es preciso recorcar que en aquellos tiempos ni se creía en la originalidad con fanatismo ni se defendia el dictamen que "la verdadera creación es dar existencia de la nada" ${ }^{9}$ Al contrario, se le concedía valor a la traducción y a la imitación como parte del adiestramiento de un escritor novel. El ilustre Alberto Lista, amigo cle Gertrudis y mentor de toda una generación de escritores, aconsejaba a sus discípulos, con toda seriedad, precisamente este tipo de ejercicio. Su propia poesía debe mucho a la imitación; él mismo nos advierte en un prólogo a sus poesías: "Mi modelo es Rioja, y mi cuidado al componer ha sido siempre revestir con las formas, la expresión y el lenguaje de este gran poeta, los pensamientos que la inspiración me sugería". ${ }^{10}$ Enteramente normal entonces que así como en poesía había imitado a Lamartine y a otros poetas, al escribir su primera novela, la joven cubana también tratara de imitar a algunos de los autores que le habían impresionado como modelos de perfección literaria.

El nombre de Chateaubriand figura en "una lista de algunas obras ce mi gusto" que la cubana envió a su amigo Ignacio Cepeda: ". . la Atcla del inmortal y divino Chateaubriand, porque te agradan todas las escenas de la naturaleza, todos los corazones primitivos, en fin, el hombre en su estado normal; y esta linda obra te satisfará"."11 En esta carta no se menciona el René, pero ¿seria verosímil que la joven amante

9 Las palabras entre comillas son de Amado Alonso, Materia y forma en poesia (Madrid, 1960) p. 301. Alonso defiende el derecho de inspirarse en otras obras literarias: "Y hay siempre la sospecha de que el poeta que se inspira en la obra ajena, lo que hace es utilizar la forma misma con habilidad de perito, retocarla y transformarla, pero no crearla. Esto es muy verdad casi siempre en escritores que no merecen la pena de ser estudiados; pero no vale como criterio general. Porque lo que una vez ha sido forma - objeto de conciencia - puede luego retornar a ser materia - mera sensación o incitación - que una nueva potencia pcética puede sacar a nueva forma". (Ibid'). Ernest Martinenche trató el mismo problema en el prefacio de La comedia espagnole en France de Hardy a Racine (París, 1900) "Peu importe que notre Corneille ou notre Molière aient emprunté une ou deux scenes de plus. Le mot d'invention n'a pas le sens matériel et grossier que le vulgaire lui donne quelquefois. Avec des parties prises à droite et à gauche, on peut faire un tout original. Se servir de ce qu'on a lu comme de ce qu'on a vu reste encore le seul moyen d'inventer".

10 En Biblioteca de autores españoles (Madrid, 1953). LXVIII, p. 273. Sobre Lista ccmo mentor de varics escritores románticos, véase J.C.J. Metford, "Lista and the Romantic Movement in Spain", en Liverpool Studies, $1^{\text {a }}$ serie (Liverpool, 1940).

11 Autobiografia y cartas, p. 116 
de literatura francesa no conociera una obra fundamental del "inmortal y divino Chateaubriand"? Además, existen las pruebas - contundentes, a nuestro parecer - que nos proporciona el cotejo de textos:

Sab, como René, nunca podrá pretender la mano de la mujer que él ama. Al darse cuenta de su situación, el mulato desespera. Trata de alejarse de Carlota y en su destierro voluntario una tarde, al regresar a su choza, se detiene al lado de un río para contemplar la puesta del sol:

...cansado del trabajo venía a la caída del sol a reposar mis miembros a orillas de este río, aquí también me aguardaban las mismas ilusiones... Todos los objetos inspiran una indefinible ternuta y al suspiro de la brisa se mezcla involuntariamente el suspiro del corazón. (IV, 486-487).12

René vuelve a su choza solitaria también a esa misma hora:

... quand le soir était venu, reprenant le chemin de ma retraite, je m'arrêtais sur les ponts pour voir se coucher le soleil... En regardant les lumières qui brillaient dans la demeure des hommes, je me transportais par la pensée au milieu des scènes de douleur et de joie qu'elles éclairaient, et je songeais que sous tant de toits habités, je n'avais pas un ami. .. (p. 363). ${ }^{13}$

Este pasaje de René:

... mais une voix du ciel semblait me dire: "Homme, la saison de ta migration n'est pas encore venue; attends que le vent de la mort se lève, alors tu céploieras ton vol vers ces régions inconnues que ton coeur demande.

12 Obras completas. (La Habana, 1914), 6 vols.

13 François-René Chateaubriand, René (Paris, 1962). Notorio es que la descripción del crepúsculo ha llegado a ser un lugar común en la poesía. En Italia se cita con frecuencia -y no solamente por eruditos y poetas- el verso de Dante: "Era già l'ora che volge il disio". Acaso Dante tenga algo que ver con la predilección de algunos poetas por este tema:

Era già l'ora che volge il disio

ai navicanti e 'ntenerisce il core

lo dì c'han detto ai dolci amici addio;

e che lo novo peregrin d'amore

punge, s'e' ode squilla di lontano

che paia il giorno pianger che si more;

(Purgatorio, VIII) 
Levez-vous vite, orages désirés, qui devez emporter René dans les espaces d'une autre vie! Ainsi disant, je marchais à grands pas, le visage enflammé, le vent sifflant dans ma chevelure, ne sentant ni pluie, ni frimas, enchanté, tourmenté, et comme possédé par le démon de mon coeur... (pp. 2x3-2I4).

pudo haber inspirado, al menos en parte, el texto de $S a b$ que sigue:

¡Vientos abrasadores del Sur! cuando habéis acudido a mis desesperados clamores, trayendo en vuestras alas las tempestades del cielo... He implorado al rayo y le he atraído en vano sobre mi cabeza... Y no ha pasado nunca la de mi corazón..." (IV, 487).

Notemos que Sab pretende eludir su destino muriendo mientras que René pide sólo que se le transporte a otra vida. Más tarde René buscará la muerte con la misma desesperación de Sab:

Grand Dieu, qui vis en secret couler mes larmes dans ces retraites sacrées, tu sais combien de fois je me jetai à tes pieds pour ta supplier de me décharger du poids de l'existance... (p. 206).

Como René, Sab no tiene amigo que comparta sus desdichas. Sólo Dios, la naturaleza y el cielo son testigos de sus lágrimas:

¡Preguntádselo a esos montes, a este río, a estas peñas! Sobre ellas he derramado mis lágrimas que el río arrastraba en su corriente. ¡Oh! ¡Teresa! preguntádselo también a este cielo que ostenta sobre nosotros sus bóvedas eternas; él sabe cuántas veces le rogué me cescargase del peso de una existencia que no le había pedido... (IV, 486).

En las montañas, René invoca a una mujer ideal:

...je m'élevois sur la montagne, appelant de toute la force de mes désirs l'idéal objet d'une flamme future; je l'embrassois dans les vents; je croyois l'entendre dans les gémissements du fleuve tout étoit ce fantôme imaginaire, et les astres dans les cieux, et le principe . même de vie dans l'univers... (p. 2 IO). 
Para Sab, Carlota aparece en todas estas visiones:

Si en las auroras de la primavera quería respirar el aire puro de los campos y despertar con toda la naturaleza a la luz primera de un nuevo día, a Carlota veía en la aurora y en el campo: la brisa era su aliento, la luz su mirar, su sonrisa el cielo. De amor me hablaban las aves que cantaban en los bosques, de amor el arroyo que murmuraba a mis pies, y de amor el gran principio de vida que anima el universo. (IV, 486).

Los dos jóvenes - Sab y René- se sienten aislados, solos frente a la incomprensión del mundo, mas lo que se encuentra intangible y vago en René se precisa y se aclara en la novela će la Avellaneda. ${ }^{14}$ Sab sufre a consecuencia de las barreras que la sociedad de su tiempo le ha impuesto:

Los hombres dirán que yo he sido infeliz por mi culpa: porque he soñado los bienes que no estaban en mi esfera, porque he querido mirar al sol, como el águila, no siendo sino un pájaro de noche. $($ IV, 537).

René intenta explicarse de esta manera:

On m'accuse de passer toujours le but que ie puis atteindre hélas! je cherche seulement un bien inconnu, dont l'instinct me poursuit. (p. 208).

El personaje de Teresa en muchos detalles recuerda la malhadada figura de Amélie, hermana de René. Se cree que Teresa es fría e indiferente a los hombres; en realidad, ama al prometido de Carlota. Sin embargo, como Amélie, ella sabe que el destino le ha sido desfavorable y se resigna a sufrir en silencio. Se da cuenta de que Sab ama a Carlota y es ella la que obliga a Sab a prometerle que no se suicidará: "No me apartaré de ti sin que me jures respetar tu vida". (IV, 495). La hermana de René exclama: "Ingtat, tu veux mourir, et ta soeur existe! Tu soupçonnes son coeur! Ne t'explique point, je sais tout; j'ai tout compris...; fais le serment de ne jamaise attender à tes jours". (p. 218). Y la carta

I4 Quizá lo vago en René se explique por el deseo de no declarar abiertamente un amor incestuoso. En cuanto a la emoción de Sab, la Avellaneda la considera natural y su prohibición se debe a la injusticia. 
que Teresa le deja a Carlota hace pensar en lo que Amélie escribe a su hermano: "Por evitarme las reflexiones que harías... dejo tu casa sin despedirme de ti sino por estas líneas". (IV, 523). En su nota Amélie lamenta: "Vous me pardonnerez conc de m'être dérobée de chez vous, comme une coupable: je n'aurois pu résister à vos prières, et cependant il falloit partir..." (p. 221). Teresa observa que ella ya había considerado retirarse a un convento: "Hace muchos años que miré el claustro como el único destino". (IV, 523). Amélie señala: "Vous savez, René, que j'ai toujours eu du penchant pour la vie religieuse". (p. 22I).

Nótese que por lo menos en dos casos las similitudes de palabras y aun de frases enteras son tales que se tendrá que sospechar que la Avellaneda, al escribir su novela, tenía el libro de Chateaubriand ante los ojos. En otras comparaciones, algunos detalles coinciden de manera tan precisa que no es posible dudar ce la influencia. Pero no se debe exagerar: René es sólo una de las novelas que la Avellaneda pudo imitar.

\section{II}

La primera alusión a Goethe que encontramos en la obra de Gertrudis Gómez de Avellaneda debe datar de I84I ó I842 cuando escribía Dos mujeres: “ $¡ E l$ Werter [sic] de Goete [sic]! ¡páginas de fuego que me presentaba su mano fría y que devoraban mis ojos en las horas de devorante insomnio!'15 ¿Tienen estas páginas, que los ojos de la Avellaneda devoraron, algo que ver con $S_{a b}$ ? Busquemos Ia respuesta en la comparación de algunos detalles.

¿El nombre de Carlota no coincide con el de la Charlotte de Goethe? ¿Y no se parece esa heroína cubana a la amiga de Werther? Carlota no toca el clavicordio como su hermana alemana pero sí la guitarra; no tiene seis hermanos pero sí goza del cariño de cuatro hermanitas y un hermano.

Como Werther, al saber que Lotte nunca será suya, Sab se va a trabajar lejos de la amada; pero ni Sab ni Werther pueden olvidar. Sab reconoce: "En vano quería apartar a Carlota de mi imaginación". (IV, 486). Wetther se queja: "Comme son image me poursuit!" (P. III)..$^{16}$

15 Dos mugeres (Madrid, 1842-1843), II, p. 90.

16 Les souffrances du jeune Werther (Paris, 1954), edición bilingüe alemánfrancés. La Avellaneda no sabía alemán; tuvo que leer Wertber en traducción; probablemente en francés. Por eso nos referiremos a la vẹrsión francesa en nuestras citas. 
A Sab Carlota no le manifiesta su cariño pero Teresa sí puede decirle: "Querido Sab". Sab contesta, "QQuerido! no, nunca lo he sido, nunca podré serlo..." (IV, 495). Werther cice: "elle (Lotte) me tendit la main en disant: Adieu, cher Werther. C'était la première fois qu'elle m'appelait ainsi!"' (p. 104).

Como Werther, Sab quiere mucho a los niños. En la novela de Goethe los niños representan para Werther la pureza del género humano porque no han sido corrompidos por la sociedad. En Sab los niños están descritos en toda su inocencia; las hermanitas de Carlota prodigan al esclavo mulato mil ternuras. Las hermanas de Lotte no se muestran menos afectuosas con Werther. Este maldice de los que envenenan a los corazones puros $\mathrm{e}$ inocentes:

Malheur, dis-je, à ceux qui se servent de l'empire qu'ils ont sur un coeur pour lui dérober les joies simples qui germent de ce coeur même! Tous les présents, toutes les amabilités du monde ne remplacent pas un instant de satisfaction de nous-mêmes, qu'une envieuse humeur de notre tyran nous a empoisonnée. (p. 35).

Sab expresa este mismo sentimiento:

Hombres crueles que hielan la sonrisa en los labios inocentes, que rasgan el velo brillante que cubre a los ojos inexpertos, y que al decir: ésta es verdad, destruyen en un momento la felicidad de toda una existencia. (IV, 480 ).

Charlotte se lleva mejor con Werther que con su marido. En cambio, Carlota no se da cuenta en los primeros capítulos que Sab es el hombre que le puede traer felicidad. Cuando niños el mulato y la criolla habian jugado juntos y aún poseen el mismo gusto por la lectura y un temperamento semejante. Sab sabe que ella seria más feliz con él:

Pero no, él no es digno de ella: ella no puede ser dichosa con Enrique Otway ... ¡ Ved aquí el motivo de mi desesperación! Carlota en brazos de un hombre era un dolor. (IV, 49r).

Werther exclama:

Elle eut été, avec moi, plus heureuse qu'avec lui! Oh! il n'est pas homme à remplir tous les voeux de ce coeur; (p. 89). 
Y también: "Il me court un frisson par tout le corps, Wilhelm, lorsqu' Albert étreint sa svelte taille". (pp. 88-89). Además, Albert se ocupa demasiado de negocios y no bastante de su esposa; algo parecido le ocurre a Jorge, quien la noche de la boda pasa varias horas leyendo y estudiando documentos en el despacho del padre de Carlota.

En la carta que deja para Carlota, Sab dice que se siente dichoso en estos últimos momentos de su vida:

¡Ah! si: la muerte era mi único deseo, mi única esperanza, y al sentir su mano fría apretar mi corazón, he gozado una alegría feroz y he levantado a Dios mi corazón para pedirle: Yo reconozco tu misericordia. (IV, 532).

Werther, que había deseado tanto morir, también se alegra cuando se aproxima la muerte:

Tout est dans silence autour de moi, et un si grand calme est en mon âme! Merci, mon Dieu, de donner à ces derniers instants cette chaleur, cette force. (p. 148 ).

Sab acaricia y besa el brazalete que Teresa le ha obsequiado (se trata de un brazalete que contiene el retrato de Carlota). Werther besa el listón que Lotte le ha regalado.

El protagonista alemán se suicida; el Werther cubano no. La Avellaneda dice que el joven se cae del caballo y que los vasos del pecho se le rompen. ¿Se podrá decir que muere de amor? ¿Es esta muerte el resultado del exceso de emoción que Werther describe de la manera siguiente?

La nature humaine a ses limites: elle peut supporter joie, peine, douleurs jusqu'à un certain degré, mais elle succombe dès que celui-ci est dépassé... (p. 53).

Werther muere evocando a Charlotte: hay una determinación, una voluntad que dirige sus últimos instantes:

Ils sont chargés. - Minuit sonne! Qu'il en soit donc ainsi! — Lotte! Lotte!. Adieu! Adieu! (p. I50). 
A Sab se le escapa la vida y él piensa en Carlota:

¡Carlota! ... acaso ahora mismo...; muera yo antes. ¡Dios mío!... mi alma vuela hacia ti..., adiós, Teresa... la pluma cae de mi mano... ¡adiós! ... yo he amado, yo he vivido... ya no vivo... pero aún amo. (IV, 539).

Algunas de estas semejanzas pueden resultar de simples coincidencias, pero teniendo en cuenta que a la joven Avellaneda le habían impresionado las "páginas de fuego" de Werther, es más probable que exista una influencia directa. Otra pregunta surge: si se parece $S a b$ a Werther, ¿no es porque René es una imitación de la obra de Goethe? No se poćrá negar la filiación entre la novela de Chateaubriand y Werther; sin embargo, obsérvese que los detalles que comparamos - Carlota, el clavicordio, los hermanitos, las palabras de cariño, el amor a los niños, la congelación de los corazones inocentes, el esposo interesado, los celos, etcétera - no tienen paralelo en René. Por otra parte hay que convenir en que la relación aquí parece menos directa que la de Réné.

\section{III}

En 1836 Gertrudis Gómez de Avellaneda había leído algunas obras de Jean-Jacques Rousseau y estas lecturas le ocasionaron ciertas dificultades: "Decían (los parientes de su padrastro) que yo era atea, y la prueba que daban era que leía las obras cee Rousseau..."17 La Nouvello Héloïse sobre todo debió impresionar a la joven cubana. De que conociera esta obra no hay duda puesto que en las primeras páginas de su Autobiografia a uno de sus novios le atribuía "el ingenio y la sensibilidad apasionada de un Saint-Preux".18

Como Saint-Preux y Werther, Sab cree en la superioridad de los que aman; sin embargo, esto no le impide sentirse completamente solo en el mundo. Si Saint-Preux dice: "Mais moi, Julie, hélas, errant, sans famille, et presque sans patrie..." $(I, 66)^{19}$ también Sab expresa un sentimiento

17 Autobiografía y cartas, p. 72.

18 Ibid., p. 45 .

19 La nouvelle Héloüse, 2 vols. (Paris, 1935). Compárese René: "Helas! j"étais seul sur la terre" (p. 215) "Sans parents, sans amis, pour ainsi dire seul sur la terre" (p. 209). "Je me trouvai bientôt plus isolé dans ma patrie que je ne l'avais été sur une terre étrangère" (pp. 204-205). Es imposible asegurar que la 
parecido: "Yo no tengo padre ni madre... soy solo en el mundo... No tengo tampoco una patria que cefender". (IV, 257).

Sab ocupa un lugar de privilegio al lado de Carlota hasta el día en que la familia de la criolla cree oportuno separar a los jóvenes. SaintPreux, preceptor en casa de la bella Julie, goza en la presencia de su amada hasta el día de su separación. Los dos protagonistas - Sab y Saint-Preux - sufren; pero al mismo tiempo se dan cuenta de que el amor también les ha proporcionado ciertos beneficios. Saint-Preux cice: "Sans toi, beauté fatale, je n'aurais jamais senti ce contraste insupportable de grandeur au fond de mon âme". ( $I, 66)$. Sab analiza el efecto de su pasión: "...paréceme que mi destino no ha siço vulgar. Una gran pasión Ilena y ennoblece una existencia. El amor y el dolor elevan el alma". (IV, 536). Y si Saint-Preux dice: "J'appris dans ma nouvelle condition que l'interêt n'est pas comme je l'avais cru, le seul mobile des actions humaines... Je conçus que le caractère général de l'homme est un amour propre..." (II, III), en su última carta, Sab revela haber descubierto algo similar: ". . . me pregunto a mí mismo si la virtud no es la fortaleza, y si la fortaleza no es el orgullo. Porque el orgullo es lo más bello". (IV, 534).

No se puede decir que el pasado de Teresa no se asemeja al de Claire d'Orbe de La Nouvelle Hélö̈se. Huérfana como Claire, Teresa vive en casa de Carlota más o menos en las mismas circunstancias en que Claire reside en el hogar de la familia d'Etange. Las dos jóvenes, al principio confidentas de la prima, terminan cumpliendo con este mismo cargo en favor del desdichado novio. Claire hasta llega a confesar cierta debilidad por el novio de su prima, y la humilde Teresa igualmente se cree vulnerable a las desdichas sentimentales del mulato: "Parecióle tarnbién que ella era capaz de amar del mismo modo y que un corazón como el de Sab era aquel que el suyo necesitaba". (IV, 488). Después dirá: "Déjame pues, seguirte a remotos climas al seno de los desiertos... iYo seré tu amiga, tu compañera, tu hermana!' (IV, 496).

En el cotejo de textos hemos tratado de fijar nuestra atención en las similitudes que pueden resultar de una influencia directa; a base de la comparación de detalles específicos quizá se concluirá que $S a b$ debe más a René y a Werther que a La Nouvelle Hélö̈sa Sin embargo, en varios casos no se podrá asegurar que la influencia provenga de una sola novela ya que la Avellaneda conocía las tres novelas que proponemos como prin-

Avellaneda se inspirara en la obra. de Rousseau y no en la de Chateaubriand; sin embargo, no hay duda de que Chateaubrianl tomó la idea de Rousseau. 
cipales fuentes literarias. Además, hay que hacer hincapié sobre el fondo sentimental e ideológico de $S a b$ - si se le puede conceder ideología a esta novelita - porque acaso derive, no exclusivamente de una novela, sino de toda la tradición literaria iniciada por La Nouvelle Hélö̈se. Rousseau, en su obra, glorifica los sentimientos nobles, y la Avellaneda también insiste en la supremacía de los afectos sobre la razón. Sab, como SaintPreux, Werther y René, trata de analizar sus desdichas, pero los chorros de lágrimas le impiden una meditación tranquila. Este aspecto lacrimoso de La Nouvelle Hélö̈se s erepite en Sab como en Wertber y René. Igualmente que en la novela de Rousseau y en Wertber, en $S a b$ se le asigna preeminencia a la vida pacífica del campo sobre la existencia agitada de la ciudad. Cuando Carlota declara su deseo de vivir en un cabaña de indio, ¿no es esto parecido a lo que dice Saint-Preux?: "Que ne puis-je couler mes jours avec toi dans ces lieux ignorés, heureux de notre bonheur et non du regard des hommes!"' (I, 60).20

Enteramente dentro de la tradición de La Nawvelle Hélö̈se se censuran en $S a b$ desde el principio hasta el final las injusticias sociales. Como Rousseau, la Avellaneda protesta contra la aristocracia de nacimiento: "¿Tienen ellos el poder de hacer hereditarios las virtudes y los talentos?" (IV, 538). Milord Edouard afirma: "Je ne connais l'égalité déshonorante que celle qui vient du caractère de l'éducation". (II, 270). Y si en $L a$ Nouvelle Hélö̈se los criados se sientan a comer en la misma mesa que el amo y su familia, asimismo pasa en Sab. La Avellaneda, además, ataca la esclavitud, ${ }^{21}$ pero es menester añadir que la crítica de la Avellaneda no concluye con esto. Acaso se inspiraba en George Sand al reprocharle a la sociedad de su tiempo sus ideas inflexibles en cuanto al matrimonio. Sobre este asunto la cubana se muestra mucho más revolucionaria que Rousseau, bien que en La Nomelle Hevoise ya exista el germen de una aversión al matrimonio. Recordemos que Claire d'Orbe dice: "S'il eût dépendu de moi, je ne me serais point mariée; mais dans notre sexe on n'achète la liberté que par l'esclavage, et il faut commencer par être servante pour devenir maîtresse un jour". (II, I6). Se sabe también que la Avellaneda había leído la obra de Montesquieu antes de $184 \mathrm{I}^{22}$ y que en la carta 16 de las Lettres Persanes Montesquieu ataca la indi-

20 En este caso la procedencia del texto de la Avellaneda también parece discutible si recordamos lo de René: "Heureux Sauvages! Oh! que ne puis-je jouir de la paix qui vous accompagne toujours!" (p. 201).

21 Véanse Obras completas, IV, 457, 485, 487, 495.

22 Cfr. Domingo Figarola-Caneda, Gertrudis Gómez de Avellameda (Madrid, 1929) p. 258. 
solubidad del matrimonio. ¿Pensaba la Avellaneda en Montesquieu al comentar el matrimonio de Carlota y Jorge? Montesquieu hace decir a sus persas que la idea de casar a personas que no congenian es equiparable a "ces tyrans qui faisaient lier des hommes vivants à des corps morts". ${ }^{23}$ Y la Avellaneda: "Tanto valdría ligar al águila con la serpiente o a un vivo con un cadáver”. (IV, 498). ¿No nos propone aquí implícitamente el divorcio como remedio a una unión mal avenida? Sab exclama ante la mala ventura de Carlota: “ $O$ Oh! ¡las mujeres! ¡Pobres y ciegas víctimas! Como los esclavos, ellas arrastran pacientemente su cadena y bajan la cabeza bajo el yugo de las leyes humanas. Sin otra guía que su corazón ignorante, eligen un dueño para toda la vida". (IV, 538). Como si esto no fuera bastante, Sab agrega que el esclavo al menos tiene la posibilidad de cambiar de dueño, pero - "la mujer, la mujer, cuando lleva sus manos enflaquecicas y su frente ultrajada para pedir libertad, oye al monstruo de voz sepulcral que le grita: 'En la tumba!'" (IV, 538).

Después de repasar todo lo que creemos que influyó en la composición de $S a b$, acaso se piense que la novela de la Avellaneda no es más que un pastiche de los modelos señalados. ${ }^{24} \mathrm{La}$ verdad es que $S a b$ apenas si se parece a las novelas de Goethe, Rousseau y Chateaubriand. En la novela cubana se cabalga desaforadamente a medianoche; se desatan repentinas tempestades tropicales; se narran anécdotas del pasado prehispánico de la isla; los esclavos esperan impacientemente una ocasión para vengarse de las injusticias que han sufrido. Estos diversos elementos exóticos le prestan a la novela una ambientación muy particular, y los discursos de René, los gemidos de Werther y los conceptos altruistas de Saint-Preux adquieren en las tierras cálidas de Cuba un dejo inconfundiblemente antillano. Esto porque al apropiarse ideas y detalles la joven autora los pasa por el filtro de su sensibilidad única. Ella no permite que los modelos literarios se impongan sobre su voluntad; al contrario, la joven Gertrudis somete las situaciones, los detalles y hasta el pensamiento de sus modelos a su intención de crear una novela mucho más comprometida y atrevida

23 Lettres persanes (Paris, 1956), p. 201.

24 En Otras inquisiciones (Buenos Aires, 1960), Jorge Luis Borges imagina a Nietzsche opinando que en casos de inspiración literaria "lo importante es la transformación que una idea puede obrar en nosotros, no el mero hecho de razo. narla", (p. 103). Es que cuando se trata de un verdadero creador la inspiración sirve solamente de estimulante. A pesar de su innegable fuente española, Le Cid de Corneille conserva su sabor verdaderamente francés; de igual manera, al inspi. rarse en mitos clásicos o en asuntos bíblicos, Racine no pierde su individualidad, El hecho de que haya una filiación directa entre La Nouvelle Héloïse, Wertber y René no despoja estas obras de una existencia individual. 
que La Nouvelle Héloüse. En su gran novela Rousseau le otorga prioridad al deber sobre el amor; Goethe y Chateaubriand se preocupan por el dilema del héroe romántico que no puede aceptar su trágico destino. En cambio, la Avellaneda no admite esa inercia que agobia el espíritu de René, ni tampoco la negación de la vida que es el sucidio cie Werther; y a pesar de su sincera admiración por la obra de Rousseau, la joven autora rehusa el sacrificio al deber que representa La Nouvelle Hélö̈se.

Quizá se pueda decir sin presumir demasiado que del estudio de las fuentes literarias de Sab se saca en limpio que la Avellaneda pensaba en Goethe, Chateubriand y sobre todo en Rousseau al escribir su novelita. Desgraciadamente no se comprendió la novela; la crítica, como dice la profesora Percas Ponseti, "no la juzgó bien, sea por aplicarle normas establecidas que no le cuadran, sea por atribuirle mayor valor a lo circunstancial que a lo esencial". 25 Alberto Lista, por ejemplo, escribió a la autora: "No se olvide usted de que el mérito principal de su novela consiste en haber sabido interesar a favor de los amantes no correspondidos". ${ }^{26}$ $\mathrm{Y}$ en el Movimiento Literario, de España (Madrid, 29 de diciembre de r84 I) apareció lo siguiente: “. . la prenda que más brilla en todas las composiciones de esta joven autora es la lógica severa... quéjase de la sociedad, pero con dulce resignación sin dirigir contra ella los punzantes sarcasmos de Jorge Sand; es en una palabra, el alma que gime, y no la que acusa; el cisne que canta, y no el tigre que amenaza". ${ }^{27}$ Aun por estos dias la crítica no ha rectificado su error y sigue despistada: en 1962 E. Díez-Echarri y J. M. Roca Franquesa dicen de Sab: "un simple ensayo, con excelentes descripciones y una ambientación bien lograda". ${ }^{28}$ En verdad no se ha podido ver en Sab más que una débil novela de amor no correspondido, una novela con varios cuadros de costumbres y nada más.

¿For qué es que no se ha creído - o querido creer-en el aspecto antiesclavista de la novela? Cotarelo llegó a afirmar que "no hay naća de protesta contra la esclavitud más que el hecho de admitir en el héroe el impedimento de aspirar a su dicha". ${ }^{29}$ Acaso esta renuencia a aceptar el elemento abolicionista resulte del hecho de que indudablemente $S a b$ es.

25 Op. cit., p. 348.

26 En Figarola-Caneda, $O p$. cit., p. 151.

27 Ibid. pp. $78-79$.

$\Sigma 8$ Historia general de la literatura española e bispanoamericana (Madrid, $1962)$, p. 950 . Compárese este juicio con el de Cotarelo, Op. cit., 1929: "...pero lo que a esta novela da valor y fisonomía singulares es el ser americana, cubana $y$ el contener hermosas descripciones de la naturaleza y costumbres de aquel pais" (p. 22).

29 Op. cit., (1929), p. 22. 
muchos más que una novela antiesclavista. Una lectura cietenida nos revela que, con respecto a varias cuestiones sociales, la Avellaneda no esconde su heterodoxia. No cabe duda de que en Sab pululan ya de manera bastante abierta algunas iceas que pudieron haber sido consideradas alborotadoras en aquellos tiempos. Debajo de ese precario equilibrio de tempestades y tranquilidad en el Caribe, yace latente la amenaza de una violenta tormenta social. Para la Avellaneda el esclavo debía ser libre y la mujer tenía cierecho a una vida mejor, exenta de las graves limitaciones asignadas a ella por una sociedad no siempre justa. La esclavitud representa solamente una de las injusticias que la novelista quisiera eliminar. En Sab la joven autora arremete contra todos los que se opondrían a las nobles aspiraciones del hombre, contra todos los que limitarían la vica a los desventurados Sab y Teresa, y contra los que condenarían despiadadamente a Carlota por un error de juventud. En su significación más universal, Sab representa una vigorosa protesta contra toda servidumbre.

Figarola-Caneda observa que en $E l$ Museo se dijo que la primera edición de $S a b$ fue "secuestrada y retirada de la circulación por los mismos parientes de la autora, a causa de las ideas abolicionistas que encierra". ${ }^{30}$ La Avellaneda misma alude a discreciones de juventud al publicar la segunda edición de $S a b, 31$ y si es cierto lo que aduce Aurelia Castillo de González ("y tanto influjo adquirieron en su espíritu los sacerdotes nombracios [jesuitas], que atendiendo a los consejos que entonces la dieron, excluyó más tarde las novelas Sab y Dos mujeres de la colección de sus obras"), ${ }^{32}$ entonces debe entenderse que la Avellaneda temía no sólo por sus ideas abolicionistas sino también por sus opiniones sobre el divorcio y los derechos de la mujer.

Es evicente que la crítica falló al no poder situar la novela Sab en su propia tradición literaria, y al no comprender bien las intenciones de la joven Gertrudis. Esto no nos sorprende porque, en efecto, Sab era una anomalía en la España de I84I: la novelita pertenece a una tradición literaria extranjera. Lo que sí parece inconcebible, sin embargo, es que en I930 un crítico tan perspicaz como Emilio Cotarelo haya escrito que $S a b$ es la obra en que "la imitación o influencia francesas son menos

30 Op. cit., p. 77.

31 "Acaso si esta novelita se escribiese en el dia, la autora, cuyas ideas han sido modificadas, haría en ella algunas variaciones. . [la autora] espera que si las personas sensatas encuentran algunos errores esparcidos en estas páginas, no olvidarán que han sido dictadas por sentimientos algunas veces exagerados pero siempre generosos de la primera juventud", en Obras completas, IV, 403.

32 Biografía de Gertrudis Gómez de Avellaneda (La Habana, 1887), p. 68. 
visibles". ${ }^{33}$ Y mucho más inexplicable que el insigne hispanista británico E. Allison Peers, también por esos años, declarara que en $S a b$ no se percibía influencia de Chateaubriand. ${ }^{34}$ ¿Cómo interpretar estas afirmaciones equivocadas? La explicación ya nos la ha dado de manera indirecta la profesora Percas Ponseti cuando dice que lo esencial de $S a b$, lo que tiene más trascendencia en esta primera novela, es el reflejo de las inquietudes ce la joven criolla. ${ }^{35}$

A su prima Heloysa la Avellaneda escribía en I838: “. . yo creaba otros mundos en mi imaginación; ahora no tengo más que uno... está delante de mí, lo veo con todos sus prestigios, con todas sus brillantes miserias... y, sin embargo, el vacio del corazón está todavía". ${ }^{36}$ ¿No son éstos los síntomas del mal de René, Werther y Saint-Preux? Y el problema en Sevilla ¿no se presentaba un tanto como el de estos héroes románticos? Ignacio Cepeda no estaba casado, pero sí era rico y nunca se casaría con una criolla de modesta fortuna. La joven Gertrudis debió sentir la urgencia de expresar esa desolación, esa desesperación de emociones desbordantes. Sin embargo, ¿de qué manera convertir su propio drama en obra de arte? Tenía ciertamente el modelo de las novelas que tanto la habían conmovido los recursos de Chateaubriand, Goethe y Rousseau. Estos modelos podrían suplir su gran falta de experiencia en la vida y en el arte del novelista. Aprovechando sus conocimientos de lectora hace que sus modelos literarios sirvan de muletas, de apoyos provisionales que después descartará. Pero la bella cubana poseía una manera excepcional da expresión, un estilo muy personal de escribir. Las palabras y situaciones podían ser prestadas; en cambio, el tono, los titubeos, la gracia eran muy suyos. En vano se valía la joven Gertrudis de algunos detalles que le correspondian a Lötte y Werther, de discursos líricos de René, de conceptos e ideas de Saint-Preux; lo esencial de Sab - la angustia- le pertenecía a ella exclusivamente.

State University of New York at Albany

Alberto J. Carlos

33 Cotarelo, Op. cit. (1929), p. 22. Compárese Díez-Echarri y Roca Franquesa, $O p$. cit.: "Sab ... acusa menos que otras [novelas] la influencia francesa". (p. 950).

34 "Chateaubriand en España", Revista de Filologia Española (1924), p. 365.

35 También Cotarelo vio claramente que la joven Gertrudis "se entregó a su propia inspiración en aquellas ardorosas páginas". Op. cit. (1929), p. 22.

36 Figarola-Caneda, $O p$. cit., p. 260. 